\title{
PANORAMA DAS MIGRAÇÕES INTERESTADUAIS CEARENSES: ANÁLISE PARA O PERÍODO DE 1950 A 2010
}

\section{Silvana Nunes de Queiroz} Professora Adjunta do Departamento de Economia da Universidade Regional do Cariri (URCA) e Coordenadora do Observatório das Migrações no Estado do

\section{Resumo}

Este estudo tem como principal objetivo analisar o panorama das migrações interestaduais cearenses, a partir dos anos 1950, quando do início dos grandes volumes migratórios interestaduais. A interpretação dos condicionantes do processo migratório é feito a partir da abordagem histórico-estrutural, onde a migração constitui elemento da desigualdade regional pela expansão do capitalismo. Para mensurar a evolução e as alterações nas tendências migratórias interestaduais do e para o Ceará, trabalha-se com os "migrantes acumulados" (lifetime migrants), para o período de 1950 a 2010. O Anuário Estatístico do Brasil e os microdados dos Censos Demográficos (IBGE) são as principais fontes de informações. Os principais resultados mostram que, paulatinamente, desde os anos 1980, o Ceará diminui as suas perdas populacionais.

Palavras-chave: Migrações; Ceará; Desigualdade Regional 


\section{Introdução}

Este estudo tem como objetivo central analisar o panorama das migrações interestaduais cearenses (1950-2010), a partir das raízes históricas deste processo, tendo como pano de fundo a reconstrução das etapas do desenvolvimento socioeconômico do Ceará.

O problema a ser investigado se justifica por dois motivos: i) magnitude do fenômeno migratório; ii) poucos estudos se debruçaram sobre a análise desta questão. De acordo com as informações do Censo Demográfico 2010, em 01/08/2010, a população total do Ceará era de 8.448.055 milhões de habitantes, com 18\% (1.491.976 milhões) dos seus naturais residindo em outro estado.

Neste estudo parte-se do pressuposto teórico que a migração é um fenômeno social, vinculado a processos históricos e alimentada pela desigualdade econômica entre as regiões (SINGER, 1980). Direção e tipos migratórios serão compreendidos à luz de uma perspectiva histórica - relacionados com os desdobramentos de processos anteriores. Portanto, combina-se a investigação histórica com a análise econômica, onde as migrações são interpretadas como uma questão macrosocial resultante da desigualdade regional (MASSEY, 1990).

Em termos empíricos trabalha-se com o estoque de migrantes (migrante acumulado), que considera os sobreviventes ou aqueles que não reemigraram durante o período intercensitário. A fonte de informações provém do Anuário Estatístico do Brasil de 1950 e 1960 e dos microdados dos Censos Demográficos de 1970, 1980, 1991, 2000 e 2010. Trabalha-se, portanto, com dados dos últimos sete Censos Demográficos, procurando traçar o panorama das migrações interestaduais do e para o Ceará, bem como apontar para as principais tendências em termos de volume e direção dos fluxos.

Para o alcance dos objetivos propostos, este artigo conta com esta introdução, seguido da análise das raízes das migrações cearenses, bem como da análise do volume e redistribuição espacial do fluxo migratório interestadual. Por último, faz-se as conclusões do estudo, sumariando as principais rupturas e tendências no quadro migratório do e para o Ceará, no período de 1950 a 2010.

\section{Panorama histórico dos movimentos migratórios cearenses}

2.1 Etapa anterior a 1950: 'soldados da borracha' 
Do ponto de vista migratório, conforme a Tabela 1, em 1950, o Ceará tinha um saldo negativo acumulado com as outras Unidades da Federação, estimado em -160.947 mil pessoas, resultante da diferença entre o volume de entradas (107.539 mil) e de saídas (268.486 mil). Com relação às entradas, do Nordeste $(91,64 \%)$ veio o maior fluxo de imigrantes, com participação modesta das demais regiões, apontando para a importância da migração de curta distância. Por estado, a Paraíba $(28,86 \%)$ e o Pernambuco $(24,35 \%)$ representaram mais da metade das imigrações. Com respeito às saídas, os dados indicam algumas surpresas. Em 1950, o Nordeste $(52,79 \%)$ e o Norte $(24,15 \%)$ foram os principais destinos. Em relação aos estados, o Piauí $(19,0 \%)$ e o Maranhão $(15,0 \%)$ despontaram como os mais atrativos, superando São Paulo $(10,02 \%)$ que apareceu em terceiro lugar, seguido do Pará (10,02\%).

A explicação para o Piauí (50.965 mil ou 19,0\%) e o Maranhão (40.358 mil ou 15,0\%) serem os principais locais de 'refúgio' dos cearenses têm origem histórica. Iniciou-se com a seca de 1844 a 1846 e se intensificou durante as primeiras estiagens do século XX (secas de 1915 e de 1932). Os retirantes migraram em busca de terras férteis nos estados vizinhos, onde as estiagens foram menos intensas (ROSADO, 1981). No caso da região Norte (64.841 mil), notadamente os estados do Pará (26.912 mil ou 10,02\%) e do Amazonas (18.697 mil ou 6,96\%), a mão de obra cearense, fugida das secas do final do século XIX, foi em busca de trabalho na extração do látex, durante o primeiro ciclo da borracha (1879-1912)

A saga dos cearenses ou "soldados da borracha" em direção ao Norte se intensificou durante o segundo ciclo da borracha (1942-1945). O Governo Vargas (1930-1945), com o intuito de eliminar os vazios demográficos do Brasil e abastecer de borracha os aliados da II Guerra Mundial criou, em 1942, com sede em Fortaleza, o Serviço Especial de Mobilização de Trabalhadores para a Amazônia - SEMTA (NEVES, 2001).

Os migrantes da seca de 1877-1879 e as que se sucederam até 1950, não efetuaram traslado apenas para os estados da própria região ou para a região Norte, o Sudeste, em especial o interior paulista e o estado do Rio de Janeiro também foi palco da chegada de cearenses que foram trabalhar no cultivo do café. De acordo com Bassanezi (2000) e Lima (2010), eles foram estimulados pelo Presidente da Província do Ceará, através da concessão de passagens, a procurarem outra rota migratória além da exploração do látex na Amazônia. Assim, em 1950, o estoque acumulado de emigrantes cearenses no estado de São Paulo soma 29.054 mil pessoas $(10,82 \%)$ e no Rio de Janeiro 21.815 mil migrantes $(8,13 \%)$. 


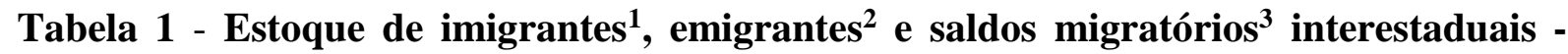
Estado do Ceará - 1950

\begin{tabular}{|c|c|c|c|c|c|}
\hline $\begin{array}{l}\text { Regiões e } \\
\text { Estados }\end{array}$ & $\begin{array}{l}\text { Imigrantes } \\
\text { (I) }\end{array}$ & $(\%)$ & $\begin{array}{l}\text { Emigrantes } \\
\text { (E) }\end{array}$ & $(\%)$ & $\begin{array}{c}\text { Saldos } \\
\text { (I-E) }\end{array}$ \\
\hline Rondônia & 12 & 0,01 & 3.258 & 1,21 & -3.246 \\
\hline Acre & 848 & 0,79 & 14.221 & 5,30 & -13.373 \\
\hline Amazonas & 3.264 & 3,04 & 18.697 & 6,96 & -15.433 \\
\hline Rio Branco & 5 & 0,00 & 878 & 0,33 & -873 \\
\hline Pará & 2.312 & 2,15 & 26.912 & 10,02 & -24.600 \\
\hline Amapá & 14 & 0,01 & 875 & 0,33 & -861 \\
\hline NORTE & 6.455 & 6,00 & 64.841 & 24,15 & -58.386 \\
\hline Maranhão & 2.205 & 2,05 & 40.358 & 15,03 & -38.153 \\
\hline Piauí & 7.126 & 6,63 & 50.965 & 18,98 & -43.839 \\
\hline Rio Grande do Norte & 15.980 & 14,86 & 7.595 & 2,83 & 8.385 \\
\hline Paraíba & 31.031 & 28,86 & 10.281 & 3,83 & 20.750 \\
\hline Pernambuco & 26.182 & 24,35 & 25.714 & 9,58 & 468 \\
\hline Alagoas & 14.971 & 13,92 & 2.201 & 0,82 & 12.770 \\
\hline Sergipe & 253 & 0,24 & 332 & 0,12 & -79 \\
\hline Bahia & 799 & 0,74 & 4.293 & 1,60 & -3.494 \\
\hline NORDESTE & 98.547 & 91,64 & 141.739 & 52,79 & -43.192 \\
\hline Minas Gerais & 275 & 0,26 & 2.064 & 0,77 & -1.789 \\
\hline Espírito Santo & 120 & 0,11 & 828 & 0,31 & -708 \\
\hline Rio de Janeiro & 987 & 0,92 & 21.815 & 8,13 & -20.828 \\
\hline São Paulo & 650 & 0,60 & 29.054 & 10,82 & -28.404 \\
\hline SUDESTE & 2.032 & $\mathbf{1 , 8 9}$ & 53.761 & 20,02 & -51.729 \\
\hline Paraná & 41 & 0,04 & 2.917 & 1,09 & -2.876 \\
\hline Santa Catarina & 37 & 0,03 & 106 & 0,04 & -69 \\
\hline Rio Grande do Sul & 268 & 0,25 & 397 & 0,15 & -129 \\
\hline SUL & 346 & $\mathbf{0 , 3 2}$ & 3.420 & 1,27 & -3.074 \\
\hline Mato Grosso & 130 & 0,12 & 2.587 & 0,96 & -2.457 \\
\hline Goiás & 29 & 0,03 & 2.138 & 0,80 & -2.109 \\
\hline CENTRO-OESTE & 159 & $\mathbf{0 , 1 5}$ & 4.725 & 1,76 & -4.566 \\
\hline TOTAL CEARÁ & $\mathbf{1 0 7 . 5 3 9}$ & 100,00 & 268.486 & 100,00 & -160.947 \\
\hline
\end{tabular}

Fonte: Elaboração própria a partir do Anuário Estatístico do Brasil (IBGE) - 1950.

Nota: Para efeito de comparação, Fernando de Noronha foi somado a Pernambuco; Distrito Federal somado ao Rio de Janeiro.

Neste contexto, em 1950, o Ceará apresentou saldo migratório negativo com todas as cinco Grandes Regiões, especialmente com o Norte (-58.386 mil), Sudeste (-51.729 mil) e Nordeste (-43.192 mil). Por estado perdeu mais população para o Piauí (-43.839 mil), Maranhão (-38.153 mil), São Paulo (-28.404 mil) e Pará (24.600 mil). Por outro lado, ganhou somente de quatro Unidades da Federação: Paraíba (20.750 mil), Alagoas (12.770 mil), Rio Grande do Norte (8.385 mil) e Pernambuco (468), todos localizados no Nordeste.

Em suma, até 1950, os retirantes cearenses, fugidos da seca e do desemprego, começaram a se 'espalhar' por diversos pontos do Brasil, praticando, ao mesmo tempo, migração de curta e de longa distância, seja para a extração de borracha na região Norte, o cultivo de arroz no Maranhão ou plantio e colheita de café no interior paulista e fluminense.

\footnotetext{
${ }^{1}$ Pessoa não nascida no Ceará que, nas datas dos Censos Demográficos, residia nesta UF.

${ }^{2}$ Pessoa nascida no Ceará que, nas datas dos Censos Demográficos, residia em outra UF.

${ }^{3}$ Resultado da diferença entre imigrantes e emigrantes
} 
2.2 Anos 1950: a marcha para o Maranhão

A concentração da indústria na região Sudeste, durante o Plano de Metas (1956-1961), no governo de Juscelino Kubitschek, agravou os desequilíbrios regionais e, intensificou as correntes migratórias de Minas Gerais e do Nordeste em direção ao Sudeste, especialmente para o estado de São Paulo (BRITO, 1999).

Com a criação de uma gama de órgãos públicos, a década 1950 representou, para o Nordeste, o início de uma nova etapa no seu desenvolvimento econômico e industrial. Em 1952 foram criados o Banco do Nordeste do Brasil (BNB), com a função de ofertar crédito e financiamento público para os agricultores da região, e o Escritório Técnico de Estudos Econômicos do Nordeste (ETENE) - responsável pela elaboração de projetos - financiados pelo BNB - para o desenvolvimento do Nordeste. Tem-se, portanto, os primeiros passos para uma política de desenvolvimento regional (ALENCAR; ALVES, 2006).

Em termos migratórios, estas primeiras medidas de combate aos desequilíbrios regionais não surtiu efeito, mostrando a defasagem de 'time' entre dinâmica econômica e dinâmica migratória, isto porque, o saldo migratório acumulado triplicou de -160.947 mil pessoas para -482.462 mil (Tabelas 1 e 2).

Com relação às entradas, em 1960, o Nordeste $(91,38 \%)$ se mantém como principal área de origem. Por estado, a Paraíba (31,38\%) e o Pernambuco (20,03\%) também permaneceram como as principais Unidades Federativas a enviarem população. No que diz respeito às saídas, esta revelou novas tendências. O Nordeste $(49,88 \%)$ continuou como principal região de destino, porém o Sudeste passou a figurar como segunda localidade mais atrativa (era a região Norte, em 1950), com estoque de 128.776 mil (21,77\%) imigrantes, contra 91.019 mil $(15,39 \%)$ do Norte. A troca de posto entre as regiões refletiu sobre o posicionamento dos estados. O Maranhão (30,30\%) tornou-se a principal porta de entrada, seguido de longe por São Paulo $(11,94 \%)$ e o Piauí $(10,38 \%)$ que, no decênio anterior, figurava como principal destino.

As perdas migratórias cresceram e o saldo migratório com as regiões se alterou, mantendo-se, porém, negativo com todas elas. Em 1950, as maiores trocas negativas tinham sido para o Norte (Tabela 1), uma década depois foi para o Nordeste (-195.369 mil), Sudeste (-126.222 mil) e Norte (-85.451 mil). Devido à expansão da fronteira agrícola do Centro Oeste e a construção de Brasília, as perdas populacionais para esta região começaram a se avolumarem, com saldo migratório acumulado de -40.743 mil pessoas, em 1960, contra 4.566 habitantes, em 1950 (Tabelas 1 e 2). Em nível estadual, o Censo Demográfico de 1960 
também revelou mudanças, com trocas acumuladas mais expressivas para o Maranhão (175.241 mil), São Paulo (-69.742 mil), Piauí (-52.394 mil) e Rio de Janeiro (-49.812 mil).

Em dez anos intensificaram-se as migrações de longa distância, com São Paulo e o Rio de Janeiro começando a despontarem como principais polos de atração. No caso do Maranhão, o grande afluxo em direção a este estado, data entre as décadas de 1940 e 1960, época em que o Ceará foi castigado por secas e marcado pela concentração de latifúndios (TROVÃO, 2008; BARBOSA, 2008).

Tabela 2 - Estoque de imigrantes, emigrantes e saldos migratórios interestaduais Estado do Ceará - 1960

\begin{tabular}{|c|c|c|c|c|c|}
\hline $\begin{array}{c}\text { Regiões e } \\
\text { Estados }\end{array}$ & $\begin{array}{l}\text { Imigrantes } \\
\text { (I) }\end{array}$ & $(\%)$ & $\begin{array}{c}\text { Emigrantes } \\
\text { (E) }\end{array}$ & $(\%)$ & $\begin{array}{c}\text { Saldos } \\
\text { (I-E) }\end{array}$ \\
\hline Rondônia & 54 & 0,05 & 7.534 & 1,27 & -7.480 \\
\hline Acre & 622 & 0,57 & 13.808 & 2,33 & -13.186 \\
\hline Amazonas & 2.652 & 2,43 & 19.678 & 3,33 & -17.026 \\
\hline Roraima & 7 & 0,01 & 1.488 & 0,25 & -1.481 \\
\hline Pará & 2.201 & 2,02 & 47.115 & 7,97 & -44.914 \\
\hline Amapá & 32 & 0,03 & 1.396 & 0,24 & -1.364 \\
\hline NORTE & 5.568 & 5,11 & 91.019 & 15,39 & -85.451 \\
\hline Maranhão & 3.969 & 3,64 & 179.210 & 30,30 & -175.241 \\
\hline Piauí & 8.984 & 8,24 & 61.378 & 10,38 & -52.394 \\
\hline Rio Grande do Norte & 20.086 & 18,43 & 7.964 & 1,35 & 12.122 \\
\hline Paraíba & 34.207 & 31,38 & 8.862 & 1,50 & 25.345 \\
\hline Pernambuco & 21.831 & 20,03 & 24.925 & 4,21 & -3.094 \\
\hline Alagoas & 9.163 & 8,41 & 3.165 & 0,54 & 5.998 \\
\hline Sergipe & 406 & 0,37 & 450 & 0,08 & -44 \\
\hline Bahia & 973 & 0,89 & 9.034 & 1,53 & -8.061 \\
\hline NORDESTE & 99.619 & 91,38 & 294.988 & 49,88 & -195.369 \\
\hline Minas Gerais & 406 & 0,37 & 5.995 & 1,01 & -5.589 \\
\hline Espírito Santo & 123 & 0,11 & 1.202 & 0,20 & -1.079 \\
\hline Rio de Janeiro & 1.152 & 1,06 & 50.964 & 8,62 & -49.812 \\
\hline São Paulo & 873 & 0,80 & 70.615 & 11,94 & -69.742 \\
\hline SUDESTE & 2.554 & 2,34 & 128.776 & 21,77 & -126.222 \\
\hline Paraná & 326 & 0,30 & 34.669 & 5,86 & -34.343 \\
\hline Santa Catarina & 199 & 0,18 & 187 & 0,03 & 12 \\
\hline Rio Grande do Sul & 397 & 0,36 & 743 & 0,13 & -346 \\
\hline SUL & 922 & $\mathbf{0 , 8 5}$ & 35.599 & 6,02 & -34.677 \\
\hline Mato Grosso & 275 & 0,25 & 13.603 & 2,30 & -13.328 \\
\hline Goiás & 74 & 0,07 & 14.971 & 2,53 & -14.897 \\
\hline Distrito Federal & 0 & 0,00 & 12.518 & 2,12 & -12.518 \\
\hline CENTRO-OESTE & 349 & $\mathbf{0 , 3 2}$ & 41.092 & 6,95 & -40.743 \\
\hline TOTAL CEARÁ & 109.012 & 100,00 & 591.474 & 100,00 & -482.462 \\
\hline
\end{tabular}

Fonte: Elaboração própria a partir do Anuário Estatístico do Brasil (IBGE) - 1960.

Nota: Para efeito de comparação, Fernando de Noronha foi somado a Pernambuco; Guanabara somado ao Rio de Janeiro.

2.3 Anos 1960: desaceleração nas saídas

Com a criação da SUDENE, no final dos anos 1950, e de órgão estaduais de planejamento, na década de 1960, combinado com incentivos fiscais, investimentos de 
empresas estatais, créditos públicos (BNDES e BNB), além de recursos de empresas locais, nacionais e internacionais, a produção industrial e agropecuária do Nordeste cresceu e se modificou.

A partir disso, do ponto de vista da dinâmica migratória cearense, a década de 1960 foi bastante distinta dos anos 1950, com a diminuição na intensidade das perdas populacionais, a partir do aumento nas entradas e diminuição nas saídas, apontando para a defasagem temporal entre transformações econômicas e migrações, conforme elucidado por Patarra (2003a), no estudo sobre a relação entre 'tempos e espaços' das migrações no Brasil.

Tabela 3 - Estoque de imigrantes, emigrantes e saldos migratórios interestaduais Estado do Ceará - 1970

\begin{tabular}{|c|c|c|c|c|c|}
\hline $\begin{array}{c}\text { Regiões e } \\
\text { Estados }\end{array}$ & $\begin{array}{l}\text { Imigrantes } \\
\text { (I) }\end{array}$ & $(\%)$ & $\begin{array}{c}\text { Emigrantes } \\
\text { (E) }\end{array}$ & $(\%)$ & $\begin{array}{l}\text { Saldos } \\
\text { (I-E) }\end{array}$ \\
\hline Rondônia & 420 & 0,26 & 8.698 & 1,19 & -8.278 \\
\hline Acre & 1.191 & 0,74 & 10.220 & 1,40 & -9.029 \\
\hline Amazonas & 3.710 & 2,30 & 16.956 & 2,33 & -13.246 \\
\hline Roraima & 178 & 0,11 & 1.447 & 0,20 & -1.269 \\
\hline Pará & 3.742 & 2,31 & 52.455 & 7,19 & -48.713 \\
\hline Amapá & 179 & 0,11 & 1.434 & 0,20 & -1.255 \\
\hline NORTE & 9.420 & 5,83 & 91.210 & 12,51 & -81.790 \\
\hline Maranhão & 8.632 & 5,34 & 153.405 & 21,04 & -144.773 \\
\hline Piauí & 16.578 & 10,26 & 64.565 & 8,85 & -47.987 \\
\hline Rio Grande do Norte & 30.178 & 18,67 & 17.410 & 2,39 & 12.768 \\
\hline Paraíba & 46.330 & 28,66 & 11.496 & 1,58 & 34.834 \\
\hline Pernambuco & 26.162 & 16,18 & 40.759 & 5,59 & -14.597 \\
\hline Alagoas & 10.853 & 6,71 & 2.724 & 0,37 & 8.129 \\
\hline Sergipe & 460 & 0,28 & 701 & 0,10 & -241 \\
\hline Bahia & 1.906 & 1,18 & 13.151 & 1,80 & -11.245 \\
\hline NORDESTE & 141.099 & 87,29 & 304.211 & 41,72 & -163.112 \\
\hline Minas Gerais & 1.050 & 0,65 & 6.572 & 0,90 & -5.522 \\
\hline Espírito Santo & 131 & 0,08 & 1.127 & 0,15 & -996 \\
\hline Rio de Janeiro & 2.950 & 1,82 & 87.691 & 12,03 & -84.741 \\
\hline São Paulo & 4.063 & 2,51 & 112.787 & 15,47 & -108.724 \\
\hline SUDESTE & 8.194 & 5,07 & 208.177 & 28,55 & -199.983 \\
\hline Paraná & 1.290 & 0,80 & 45.818 & 6,28 & -44.528 \\
\hline Santa Catarina & 153 & 0,09 & 218 & 0,03 & -65 \\
\hline Rio Grande do Sul & 538 & 0,33 & 887 & 0,12 & -349 \\
\hline SUL & 1.981 & 1,23 & 46.923 & 6,44 & -44.942 \\
\hline Mato Grosso & 382 & 0,24 & 22.943 & 3,15 & -22.561 \\
\hline Goiás & 266 & 0,16 & 24.602 & 3,37 & -24.336 \\
\hline Distrito Federal & 308 & 0,19 & 31.103 & 4,27 & -30.795 \\
\hline CENTRO-OESTE & 956 & $\mathbf{0 , 5 9}$ & 78.648 & 10,79 & -77.692 \\
\hline TOTAL CEARÁ & 161.650 & 100,00 & 729.169 & 100,00 & -567.519 \\
\hline
\end{tabular}

Fonte: Elaboração própria a partir dos Microdados do Censo Demográfico de 1970 (IBGE).

Nota: Para efeito de comparação, Fernando de Noronha foi somado a Pernambuco; Guanabara somado ao Rio de Janeiro.

Quanto à origem, em 1970 (Tabela 3), permaneceu alto o estoque de imigrantes procedentes do Nordeste $(87,29 \%)$. Nos estados vizinhos: Paraíba $(28,66 \%)$, Rio Grande do Norte $(18,67 \%)$ e Pernambuco $(16,18 \%)$ continuaram como as principais áreas de origem, 
apesar do ligeiro declínio, em relação ao período anterior. Com relação às saídas, apesar de decrescente (de 49,88 para 41,72\%, entre 1960/1970), a maioria dos emigrantes residia no Nordeste. A diminuição na atratividade nordestina foi repassada para o Sudeste $(28,55 \%)$ que passou a figurar como a segunda região de destino. Por estado, Maranhão (21,04\%), São Paulo (15,47\%), Rio de Janeiro (12,03\%) e Pará (7,19\%) continuaram convergindo os maiores fluxos. Vale destacar que as saídas para o Paraná diminuiu o ímpeto (de 31.752 mil pessoas, entre 1950/1960, para 11.149 mil, entre 1960/1970), sinalizando para o fim de sua fronteira agrícola que seguiu em direção ao Centro-Oeste e a Amazônia (MARTINE, 1994).

Em termos de saldos migratórios, o Censo Demográfico de 1970 apontou para novidades, com os maiores saldos negativo com o Sudeste (-199.983 mil), que superou o Nordeste (-163.112 mil) e o Norte (-81.790 mil). Vale lembrar que, em 1950, as maiores perdas eram para a região Norte e, em 1960, para o Nordeste. No caso dos estados, os maiores saldos negativos permaneceu com o Maranhão (-144.773 mil), seguido por São Paulo (108.724 mil) e o Rio de Janeiro (-84.741 mil). Isto denota mudanças nos trajetos das migrações cearenses, predominando, a partir de então, os fluxos de longa distância, direcionados no sentido do capital, ou melhor, do desenvolvimento urbano-industrial, concentrados no Sudeste.

\subsection{Anos 1970: rumo ao Sudeste}

Conforme Cano (1997), o Sudeste, ocupando apenas 11\% do território nacional, em 1970, detinha $81 \%$ da atividade industrial do Brasil e, o estado de São Paulo, sozinho, era responsável por $58 \%$ da produção da indústria do país.

Com relação à economia Nordestina, o PIB da região, como observa Guimarães Neto (p.153, 2004): “[...] de 1970 a 1979 expandiu-se a uma taxa de 9,4\%, apoiado pelo "milagre" econômico e pela expansão que ficou conhecida por "marcha forçada" (II PND), na segunda metade da referida década".

Quanto à economia cearense, entre as décadas de 1960 e 1970, precisamente no período da Ditadura Militar (1964-1985), a atividade industrial se desenvolveu, porém, atrelada ao setor primário e concentrada na Região Metropolitana de Fortaleza (RMF). A produção estadual concentrou-se em torno de indústrias tradicionais como a têxtil, calçadista e alimentícia, beneficiada pela matéria-prima local (LIMA; LIMA, 2008).

Apesar de essas atividades serem intensivas em mão de obra, a falta de infraestrutura local e de uma política estadual de industrialização, "emperrava" o desenvolvimento do 
estado (PONTES; CAMBOTA; BIDERMAN, 2011). A permanência da disparidade regional e a possibilidade de trabalho e melhores salários alimentaram as migrações interestaduais.

Diante desta conjuntura, a década de 1970 representou a retomada das perdas populacionais do Ceará que tinham sido amenizadas, ao longo dos anos 1960. Ao considerar todo o período em estudo, o decênio 1970/1980 foi o de maior evasão migratória em sua história.

Tabela 4 - Estoque de imigrantes, emigrantes e saldos migratórios interestaduais do Estado do Ceará - 1980

\begin{tabular}{|c|c|c|c|c|c|}
\hline $\begin{array}{l}\text { Regiões e } \\
\text { Estados }\end{array}$ & $\begin{array}{l}\text { Imigrantes } \\
\text { (I) }\end{array}$ & $(\%)$ & $\begin{array}{c}\text { Emigrantes } \\
\text { (E) }\end{array}$ & $(\%)$ & $\begin{array}{l}\text { Saldos } \\
\text { (I-E) }\end{array}$ \\
\hline Rondônia & 658 & 0,32 & 14.082 & 1,27 & -13.424 \\
\hline Acre & 1.405 & 0,68 & 8.397 & 0,76 & -6.992 \\
\hline Amazonas & 4.293 & 2,08 & 21.928 & 1,98 & -17.635 \\
\hline Roraima & 395 & 0,19 & 3.331 & 0,30 & -2.936 \\
\hline Pará & 6.235 & 3,01 & 82.021 & 7,42 & -75.786 \\
\hline Amapá & 236 & 0,11 & 1.646 & 0,15 & -1.410 \\
\hline NORTE & 13.222 & 6,39 & 131.405 & $\mathbf{1 1 , 8 8}$ & -118.183 \\
\hline Maranhão & 15.635 & 7,56 & 146.695 & 13,27 & -131.060 \\
\hline Piauí & 25.735 & 12,44 & 64.460 & 5,83 & -38.725 \\
\hline Rio Grande do Norte & 32.827 & 15,87 & 22.611 & 2,04 & 10.216 \\
\hline Paraíba & 45.297 & 21,90 & 16.794 & 1,52 & 28.503 \\
\hline Pernambuco & 32.187 & 15,56 & 47.749 & 4,32 & -15.562 \\
\hline Alagoas & 11.015 & 5,33 & 4.339 & 0,39 & 6.676 \\
\hline Sergipe & 667 & 0,32 & 2.101 & 0,19 & -1.434 \\
\hline Bahia & 4.064 & 1,96 & 32.899 & 2,98 & -28.835 \\
\hline NORDESTE & 167.427 & 80,94 & 337.648 & 30,54 & -170.221 \\
\hline Minas Gerais & 1.858 & 0,90 & 13.092 & 1,18 & -11.234 \\
\hline Espírito Santo & 310 & 0,15 & 3.606 & 0,33 & -3.296 \\
\hline Rio de Janeiro & 6.755 & 3,27 & 147.729 & 13,36 & -140.974 \\
\hline São Paulo & 9.834 & 4,75 & 295.027 & 26,68 & -285.193 \\
\hline SUDESTE & 18.757 & 9,07 & 459.454 & 41,55 & -440.697 \\
\hline Paraná & 2.584 & 1,25 & 31.206 & 2,82 & -28.622 \\
\hline Santa Catarina & 242 & 0,12 & 1.127 & 0,10 & -885 \\
\hline Rio Grande do Sul & 1.158 & 0,56 & 2.415 & 0,22 & -1.257 \\
\hline SUL & 3.984 & 1,93 & 34.748 & 3,14 & -30.764 \\
\hline Mato Grosso do Sul & 337 & 0,16 & 20.213 & 1,83 & -19.876 \\
\hline Mato Grosso & 704 & 0,34 & 11.162 & 1,01 & -10.458 \\
\hline Goiás & 913 & 0,44 & 39.684 & 3,59 & -38.771 \\
\hline Distrito Federal & 1.502 & 0,73 & 71.400 & 6,46 & -69.898 \\
\hline CENTRO-OESTE & 3.456 & 1,67 & 142.459 & 12,88 & -139.003 \\
\hline TOTAL CEARÁ & 206.846 & 100,00 & 1.105 .714 & 100,00 & -898.868 \\
\hline
\end{tabular}

Fonte: Elaboração própria a partir dos Microdados do Censo Demográfico de 1980 (IBGE).

Nota: Para efeito de comparação, Fernando de Noronha foi somado a Pernambuco.

Considerando as cinco Grandes Regiões brasileiras, o Ceará manteve o saldo negativo com todas, destacando as trocas com o Sudeste (-240.714 mil), que passou de -199.983 mil migrantes, em 1970, para -440.697 mil, em 1980, demonstrando o poder de atração desta região (Tabelas 3 e 4). Com o Nordeste a tendência foi contrária à observada em decênios anteriores, com as trocas aumentando apenas em -7.109 mil pessoas (passou de -163.112 mil, 
em 1970, para -170.221 mil, em 1980). Em nível estadual há mudanças expressivas, o Censo Demográfico de 1980 apontou, pela primeira vez, para maiores saldos acumulados com São Paulo (-285.193 mil) e o Rio de Janeiro (-140.974 mil), superando as trocas com o Maranhão (-131.060 mil). Por outro lado, os saldos acumulados foram positivos somente com a Paraíba (28.503 mil), Rio Grande do Norte (10.2126 mil) e Alagoas (6.676 mil).

Quanto à origem, predomina a migração de curta distância, com 80,94\% do fluxo procedente do Nordeste - apesar da participação relativa da mesma diminuir a cada década. Em termos de Unidade da Federação, a Paraíba (21,90\%), o Rio Grande do Norte $(15,87 \%)$ e o Pernambuco $(19,56 \%)$ mantiveram-se como principais locais de residência anterior. No caso das saídas, o destino migratório se alterou, com o maior estoque de emigrantes residindo no Sudeste (41,55\% ou 459.454 mil pessoas), que desde então se tornou a principal porta de entrada para os cearenses, ao invés do Nordeste (30,54\% ou 337.648 mil migrantes). Como reflexo da tendência regional, São Paulo (26,68\% ou 295.027 mil pessoas) passou a reter o maior estoque de naturais do Ceará, posto ocupado pelo Piauí (18,98\%), em 1950 e, o Maranhão, em 1960 (30,30\%) e 1970 (21,04\%).

Em suma, de um lado, a concentração da atividade econômica, nos grandes centros urbanos do Sudeste, em especial no estado de São Paulo e, do outro lado, o baixo dinamismo da economia cearense, incapaz de gerar oportunidades de trabalho e manter a população no estado, foram elementos que contribuíram para a expulsão e alteração nos eixos dos movimentos migratórios, predominando, desde os anos 1970, a trajetória dominante CearáSudeste e Ceará-São Paulo.

\subsection{Anos 1980: alterações nas tendências migratórias}

Os anos 1980 são considerados pelos estudiosos de população como a década de ruptura nas tendências demográficas do país, em especial na dinâmica migratória. Fatores associados à adoção de políticas neoliberais, globalização e reestruturação produtiva - a partir dos novos padrões de acumulação do capital, conjugados com a crise econômica e políticas de desenvolvimento regional, ocasionaram alterações na reconfiguração do espaço econômico e redistribuição espacial da população brasileira (DINIZ, 1995; FERREIRA; LEMOS, 2000).

No que diz respeito ao Ceará, o ano de 1987 é considerado por alguns estudiosos da dinâmica econômica regional, como o início de uma "nova" concepção na administração da máquina estatal. O recém-eleito governador elegeu como meta principal promover o desenvolvimento econômico do estado (VASCONCELOS; ALMEIDA; SILVA, 1999). 
O ajuste nas finanças públicas ${ }^{4}$ foi definido como o primeiro e mais importante passo para o alcance do desenvolvimento. O Governo partia do pressuposto de que somente com a reforma fiscal seria possível obter recursos para aumentar os investimentos nas áreas sociais e de infraestrutura básica (sistema de transporte: malha rodoviária, portuária, aeroporto; energia, saneamento básico, recursos hídricos etc.), sendo possível atrair novos investimentos (QUEIROZ; COSTA JÚNIOR, 2008).

Outra característica marcante foi à política de incentivos fiscais e/ou "guerra fiscal". O programa de incentivo fiscal tinha o benefício aumentado (redução da carga tributária) à medida que as empresas se distanciassem de Fortaleza e se dirigissem para o interior do estado. Tais medidas permitiram atrair significativos empreendimentos, destacando-se os investimentos na indústria calçadista e têxtil (QUEIROZ; COSTA JÚNIOR, 2008).

Diante desta conjuntura, a partir dos anos 1980, o ritmo de crescimento da economia cearense seguiu na contramão da dinâmica observada para o país. O PIB do Ceará, no intervalo 1980-1990, conhecido na literatura econômica como a 'década perdida', cresceu três vezes mais $(4,04 \%)$ em relação ao do Brasil $(1,21 \%)$, com reflexo sobre as migrações, a partir do arrefecimento nas saídas e o aumento no número de entradas (QUEIROZ, 2003).

Em relação à origem, o Nordeste $(71,31 \%)$ continuou enviando o maior fluxo de imigrantes, mas a região Sudeste $(16,88 \%)$, paulatinamente, permaneceu aumentando a sua participação. As demais regiões tem pouca contribuição, juntas contribuíram com cerca de $12 \%$ das entradas. Por estado, a Paraíba (16,41\%), o Pernambuco $(13,35 \%)$ e o Rio Grande do Norte $(13,32 \%)$ mantiveram-se como principais áreas de residência anterior, porém, o Rio de Janeiro (aumentou de 3,27\%, em 1980, para 5,57\%, em 1991) e São Paulo tiveram os maiores ganhos (passou de 4,75\% para 9,78\%) no intervalo em questão.

No que tange aos destinos, os anos 1980, ratifica a tendência vislumbrada na década de 1970, com o Sudeste $(45,26 \%)$ consolidando-se como principal porta de entrada, com $26,68 \%$ do fluxo direcionado para o estado de São Paulo e 12,21\% para o Rio de Janeiro. Por sua vez, o Nordeste que, em 1950, reteve mais da metade $(52,80 \%)$ das saídas, em 1991, mantém-se em segundo lugar, mas com participação de 24,63\%. O Maranhão $(8,82 \%)$ e o Piauí $(4,72 \%)$ continuam atraindo os principais fluxos da região, decorrência do elevado número de migrantes que se dirigiu para estes estados até 1960.

\footnotetext{
${ }^{4} \mathrm{O}$ controle nas finanças públicas do Ceará teve início antes da crise fiscal brasileira, assim como da implementação da Lei de Responsabilidade Fiscal. Configura, desde então, o Ceará, com situação financeira distinta da maioria dos estados brasileiros, "inspirando" confiança nos investidores (QUEIROZ; COSTA JÚNIOR, 2008).
} 
Tabela 5 - Estoque de imigrantes, emigrantes e saldos migratórios interestaduais Estado do Ceará - 1991

\begin{tabular}{|c|c|c|c|c|c|}
\hline $\begin{array}{l}\text { Regiões e } \\
\text { Estados }\end{array}$ & $\begin{array}{c}\text { Imigrantes } \\
\text { (I) }\end{array}$ & $(\%)$ & Emigrantes (E) & $(\%)$ & $\begin{array}{c}\text { Saldos } \\
\text { (I-E) }\end{array}$ \\
\hline Rondônia & 976 & 0,37 & 26.366 & 1,93 & -25.390 \\
\hline Acre & 1.468 & 0,55 & 7.389 & 0,54 & -5.921 \\
\hline Amazonas & 5.368 & 2,01 & 26.819 & 1,97 & -21.451 \\
\hline Roraima & 481 & 0,18 & 9.531 & 0,70 & -9.050 \\
\hline Pará & 10.472 & 3,92 & 111.635 & 8,18 & -101.163 \\
\hline Amapá & 624 & 0,23 & 3.021 & 0,22 & -2.397 \\
\hline Tocantins & 70 & 0,03 & 17.761 & 1,30 & -17.691 \\
\hline NORTE & 19.459 & 7,29 & 202.521 & 14,85 & -183.062 \\
\hline Maranhão & 24.742 & 9,26 & 120.323 & 8,82 & -95.581 \\
\hline Piauí & 33.696 & 12,62 & 64.439 & 4,72 & -30.743 \\
\hline Rio Grande do Norte & 35.585 & 13,32 & 30.778 & 2,26 & 4.807 \\
\hline Paraíba & 43.824 & 16,41 & 18.391 & 1,35 & 25.433 \\
\hline Pernambuco & 35.647 & 13,35 & 52.180 & 3,83 & -16.532 \\
\hline Alagoas & 8.314 & 3,11 & 4.974 & 0,36 & 3.340 \\
\hline Sergipe & 1.107 & 0,41 & 3.095 & 0,23 & -1.988 \\
\hline Bahia & 7.551 & 2,83 & 41.802 & 3,06 & -34.251 \\
\hline NORDESTE & 190.466 & 71,31 & 335.982 & 24,63 & -145.516 \\
\hline Minas Gerais & 3.329 & 1,25 & 19.421 & 1,42 & -16.091 \\
\hline Espírito Santo & 748 & 0,28 & 6.306 & 0,46 & -5.558 \\
\hline Rio de Janeiro & 14.882 & 5,57 & 166.550 & 12,21 & -151.668 \\
\hline São Paulo & 26.125 & 9,78 & 425.090 & 31,16 & -398.965 \\
\hline SUDESTE & 45.083 & 16,88 & 617.366 & 45,26 & -572.283 \\
\hline Paraná & 2.798 & 1,05 & 26.886 & 1,97 & -24.088 \\
\hline Santa Catarina & 449 & 0,17 & 3.058 & 0,22 & -2.608 \\
\hline Rio Grande do Sul & 1.779 & 0,67 & 4.237 & 0,31 & -2.458 \\
\hline SUL & 5.026 & 1,88 & 34.181 & 2,51 & -29.155 \\
\hline Mato Grosso do Sul & 803 & 0,30 & 20.711 & 1,52 & -19.908 \\
\hline Mato Grosso & 618 & 0,23 & 19.763 & 1,45 & -19.145 \\
\hline Goiás & 2.331 & 0,87 & 44.779 & 3,28 & -42.448 \\
\hline Distrito Federal & 3.293 & 1,23 & 88.710 & 6,50 & -85.417 \\
\hline CENTRO-OESTE & 7.044 & 2,64 & 173.963 & 12,75 & -166.919 \\
\hline TOTAL CEARÁ & 267.079 & 100,00 & 1.364 .013 & 100,00 & -1.096 .934 \\
\hline
\end{tabular}

Fonte: Elaboração própria a partir dos Microdados do Censo Demográfico de 1991 (IBGE).

Em síntese, ao longo dos anos 1980, ficaram evidentes as mudanças no processo migratório cearense, com destaque para o descenso nas suas perdas populacionais, a partir da diminuição nas saídas e o aumento nas entradas. Tais resultados ratificam a proposição de Pacheco e Patarra (1997) que, a partir da década de oitenta, se iniciam as mais notáveis transformações na dinâmica populacional brasileira.

2.6 Anos 1990: declínio nas perdas populacionais

Seguindo a tendência dos anos 1980, a economia brasileira passou por profundas transformações estruturais, durante a década de 1990. A opção do Governo pela estabilização dos preços - via Plano Real, conjugado com a tríade - globalização, políticas neoliberais e reestruturação produtiva - refletiram, de um lado, no controle da inflação e, do outro, no 
baixo crescimento econômico e aumento do desemprego, com destaque para o setor secundário (QUEIROZ, 2003).

Com dinâmica econômica contrária a vivenciada pelo país e o Nordeste, à economia e o mercado de trabalho formal cearense mantiveram-se com indicadores acima da média nacional e regional, com efeitos sobre a diminuição nas perdas populacionais. Neste contexto favorável a economia e ao mercado de trabalho cearense, a década de 1990 ratifica a tendência verificada nos anos 1980 - com o Ceará apresentando perda populacional cada vez menor.

De acordo com a Tabela 6, em 2000, a distribuição dos saldos migratórios não se alterou - as maiores perdas do Ceará permaneceram para o Sudeste (-706.554 mil), Norte (196.173 mil) e Centro Oeste (-190.042 mil), com as menores trocas acumuladas efetuando-se com o Nordeste (-111.983 mil) e o Sul (-31.337 mil), revelando a preferência pelas migrações de longa distância.

Estes resultados mostrou que, apesar do Sudeste (notadamente o estado de São Paulo, com trocas negativas em -486.956 mil migrantes e o Rio de Janeiro com -187.15 mil) se destacar como principal área de atração, duas outras regiões tem atraído expressivo volume de cearenses. A região Norte, principal área de destino, em 1950 (ciclo da borracha), em 2000, figurou em segundo lugar nas trocas acumuladas negativas, especialmente com o Pará (101.550 mil migrantes). O Centro Oeste, desde 1980, posiciona-se como terceira maior região de destino, com crescimento nas trocas negativas, especialmente para o Distrito Federal (87.302 mil) e Goiás (-62.340 mil). Esta atração migratória foi devido à expansão da região, a partir dos anos 1950, com a construção da Capital Federal do país e da rodovia BelémBrasília, além da expansão de sua fronteira agrícola (MARTINE; CAMARGO, 1984; MOREIRA, 1987; SOUZA, 2006).

Em 2000, o destino mantém a inclinação observada em 1980 e em 1991, com o Sudeste (49,45\%), notadamente o estado de São Paulo (33,79\%) e do Rio de Janeiro $(13,23 \%)$, registrando os maiores estoques acumulados de emigrantes, ratificando a sua posição de área de atração. No Nordeste $(21,02 \%)$ o destino preferido permaneceu entre o Maranhão (6,88\%) e o Piauí (3,95\%). As demais regiões mantêm-se com baixa participação, com $14,18 \%$ residindo no Norte; $12,77 \%$ no Centro Oeste e somente 2,57\% no Sul. Nestas regiões os estados com maiores atratividades foram: Pará (7,41\%), Distrito Federal (5,97\%) e Goiás $(4,12 \%)$. 
Tabela 6 - Estoque de imigrantes, emigrantes e saldos migratórios interestaduais Estado do Ceará - 2000

\begin{tabular}{|c|c|c|c|c|c|}
\hline $\begin{array}{l}\text { Regiões e } \\
\text { Estados }\end{array}$ & $\begin{array}{c}\text { Imigrantes } \\
\text { (I) }\end{array}$ & $(\%)$ & $\begin{array}{c}\text { Emigrantes } \\
\text { (E) }\end{array}$ & $(\%)$ & $\begin{array}{c}\text { Saldos } \\
\text { (I-E) }\end{array}$ \\
\hline Rondônia & 2.344 & 0,66 & 26.584 & 1,67 & -24.241 \\
\hline Acre & 1.951 & 0,55 & 7.865 & 0,49 & -5.914 \\
\hline Amazonas & 6.921 & 1,94 & 36.029 & 2,26 & -29.109 \\
\hline Roraima & 597 & 0,17 & 12.542 & 0,79 & -11.945 \\
\hline Pará & 16.448 & 4,61 & 117.998 & 7,41 & -101.550 \\
\hline Amapá & 916 & 0,26 & 4.382 & 0,28 & -3.467 \\
\hline Tocantins & 449 & 0,13 & 20.396 & 1,28 & -19.948 \\
\hline NORTE & 29.625 & 8,31 & 225.798 & 14,18 & -196.173 \\
\hline Maranhão & 32.335 & 9,07 & 109.568 & 6,88 & -77.233 \\
\hline Piauí & 43.719 & 12,26 & 62.988 & 3,95 & -19.270 \\
\hline Rio Grande do Norte & 36.340 & 10,19 & 33.277 & 2,09 & 3.062 \\
\hline Paraíba & 43.645 & 12,24 & 21.214 & 1,33 & 22.431 \\
\hline Pernambuco & 43.936 & 12,32 & 52.157 & 3,27 & -8.221 \\
\hline Alagoas & 8.950 & 2,51 & 5.472 & 0,34 & 3.478 \\
\hline Sergipe & 1.664 & 0,47 & 3.911 & 0,25 & -2.247 \\
\hline Bahia & 12.277 & 3,44 & 46.259 & 2,90 & -33.982 \\
\hline NORDESTE & 222.865 & 62,49 & 334.848 & 21,02 & -111.983 \\
\hline Minas Gerais & 5.427 & 1,52 & 29.935 & 1,88 & -24.509 \\
\hline Espírito Santo & 954 & 0,27 & 8.893 & 0,56 & -7.938 \\
\hline Rio de Janeiro & 23.509 & 6,59 & 210.660 & 13,23 & -187.152 \\
\hline São Paulo & 51.241 & 14,37 & 538.197 & 33,79 & -486.956 \\
\hline SUDESTE & 81.131 & 22,75 & 787.686 & 49,45 & -706.554 \\
\hline Paraná & 4.119 & 1,15 & 27.929 & 1,75 & -23.810 \\
\hline Santa Catarina & 1.113 & 0,31 & 6.189 & 0,39 & -5.076 \\
\hline Rio Grande do Sul & 4.419 & 1,24 & 6.870 & 0,43 & -2.451 \\
\hline SUL & 9.652 & 2,71 & 40.988 & 2,57 & -31.337 \\
\hline Mato Grosso do Sul & 1.044 & 0,29 & 21.167 & 1,33 & -20.123 \\
\hline Mato Grosso & 1.296 & 0,36 & 21.574 & 1,35 & -20.278 \\
\hline Goiás & 3.339 & 0,94 & 65.679 & 4,12 & -62.340 \\
\hline Distrito Federal & 7.715 & 2,16 & 95.017 & 5,97 & -87.302 \\
\hline CENTRO-OESTE & 13.394 & 3,76 & 203.436 & 12,77 & -190.042 \\
\hline TOTAL CEARÁ & 356.668 & 100,00 & 1.592 .756 & 100,00 & -1.236 .088 \\
\hline
\end{tabular}

Fonte: Elaboração própria a partir dos Microdados do Censo Demográfico 2000 (IBGE).

2.7 Anos 2000: reversão do processo migratório?

A primeira década do século XXI é marcada pela recuperação do dinamismo econômico do país, especialmente, a partir de 2004. O crescimento médio do PIB no intervalo de 2004 a 2010 foi de 4,4\% (SERRANO; SUMA, 2011), com impactos positivos sobre a evolução na estrutura social brasileira. Mesmo com a crise financeira internacional no último trimestre de 2008 e primeiro trimestre de 2009, o Brasil não interrompeu o ciclo de progresso social vivenciado nos últimos sete anos (QUADROS, 2011).

No que concerne ao Ceará, durante a primeira década do século XXI, o crescimento do PIB $(4,63 \%)$ manteve-se praticamente inalterado em relação à década anterior (4,57\%), com a diferença diminuindo para $1 \%$ em relação ao país que, cresceu 3,62\%, entre 2000/2010 
(IPECE, 2011a). Tal dinâmica refletiu sobre o mercado de trabalho estadual que, ratificou a tendência observada na década de 1990 - com aumento na oferta de vagas ${ }^{5}$.

Com relação às migrações interestaduais cearenses, estas parecem sentir o recente quadro de melhorias sociais e econômicas no país e no estado. O Censo Demográfico 2010 apontou para o expressivo declínio na participação relativa de naturais do Ceará morando em outros estados que, passou de 21,43\%, em 2000, para 17,66\%, em 2010 (Gráfico 1). Neste mesmo intervalo, a proporção de não naturais residentes no Ceará, passou de 4,80\% para 4,56\%. Com exceção de 2010, desde 1970, o contingente de não naturais na população residente do estado vem crescendo de maneira ininterrupta (aumentou de 3,71\%, em 1970, para 4,80\%, em 2000). Isso sugere que, paulatinamente, o Ceará está diminuindo as suas perdas populacionais, a partir do aumento nas entradas e o declínio nas saídas (Gráfico 1).

Gráfico 1 - Participação relativa da população emigrante e imigrante (estoque acumulado) no total da população residente no Ceará $(\%)$ - Estado do Ceará - 19502010

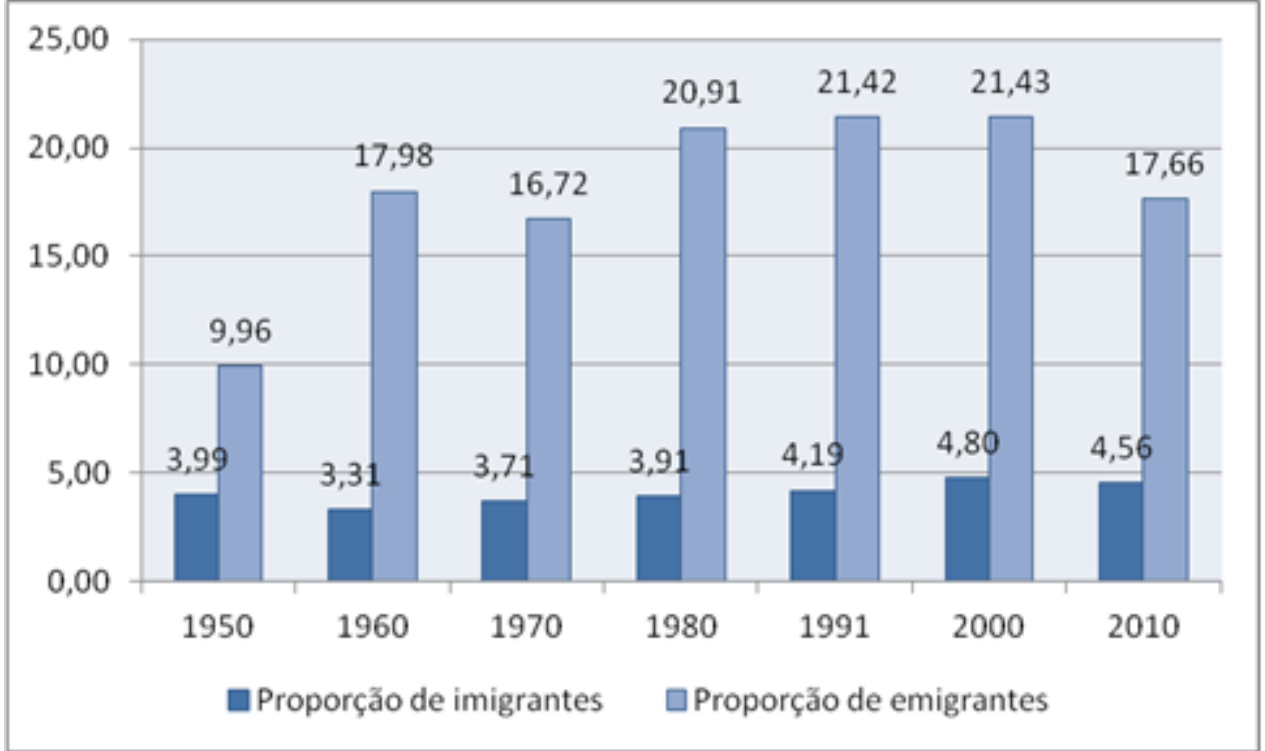

Fonte: Elaboração própria a partir do Anuário Estatístico do Brasil - 1950 e 1960; Microdados dos Censos Demográficos de 1970, 1980, 1991, 2000 e 2010 (IBGE).

O Gráfico 2 confirma esta assertiva. Ao longo dos sete decênios em estudo, pela primeira vez, constatou-se a redução nas saídas que, diminuíram de 1.592 .756 milhões de pessoas para 1.491.976 milhões, entre 2000/2010. Por sua vez, as entradas permaneceram crescentes, com aumento de 356.668 mil habitantes para 385.112 mil, no referido intervalo. A

\footnotetext{
${ }^{5}$ Vale frisar que, estudos sobre o mercado de trabalho cearense, revelam que a maioria das vagas criadas são precárias e marcada por alta rotatividade. Maiores detalhes veja Costa (2011); Aparício e Queiroz, (2011); Silva Filho, Queiroz e Clementino (2012).
} 
partir desta dinâmica, pela primeira vez, o saldo migratório declinou de um estoque de 1.236.088 milhões de pessoas, para -1.106.864 milhões, entre 2000/2010.

Gráfico 2 - Evolução no volume de imigrantes, emigrantes e saldos migratórios interestaduais (estoque acumulado) - Estado do Ceará - 1950-2010

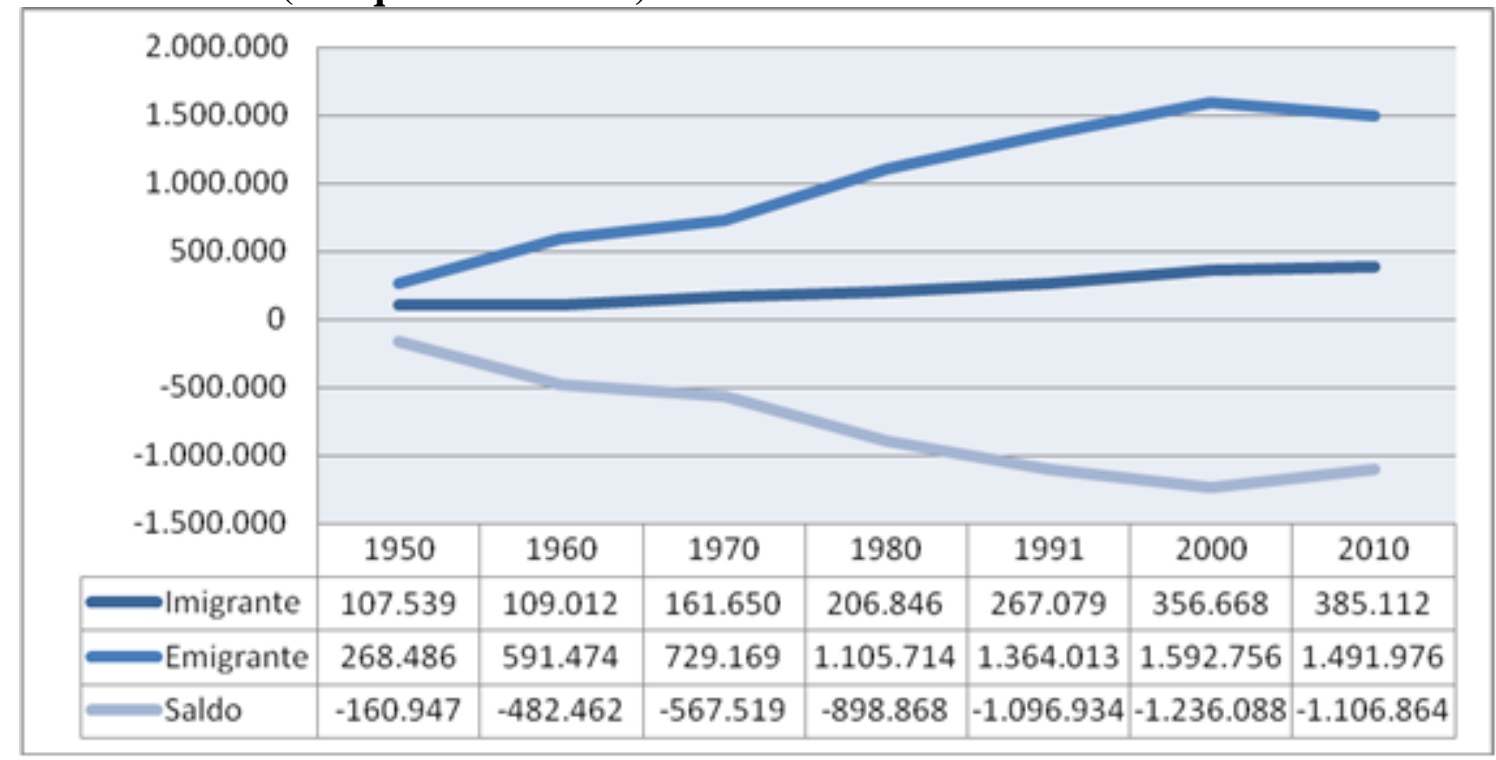

Fonte: Elaboração própria a partir do Anuário Estatístico do Brasil - 1950 e 1960; Microdados dos Censos Demográficos de 1970, 1980, 1991, 2000 e 2010 (IBGE).

Os resultados visualizados na Tabela 7 apontaram para outra novidade - as perdas populacionais entre o Ceará e as regiões se arrefeceram, com diminuição para o Norte (de 196.173 mil migrantes para -165.145 mil), Nordeste (de -111.983 mil pessoas para -95.602 mil), Sudeste (de -706.554 mil habitantes para -630.976 mil) e Centro-Oeste (de -190.042 mil pessoas para -181.564 mil), no intervalo 2000/2010. Somente para o Sul, o Ceará aumentou sutilmente as suas perdas acumuladas que, no intervalo em estudo, passou de um saldo de 31.337 mil migrantes para -33.570 mil.

Com relação à procedência, desde 1950 o Nordeste (passou de 91,64\%, em 1950, para $58,0 \%, 2010)$ envia os maiores contingentes humanos para o Ceará. A região Sudeste que, a cada Censo Demográfico, aumentou a sua participação relativa no total de imigrantes, em 2010, apareceu em segundo lugar, ao passar de 1,89\% para 25,97\%, entre 1950/2010. As demais regiões apresentaram participação modesta, com poucas alterações ao longo dos sete decênios em estudo. Por estado, o Censo Demográfico 2010 ratificou a tendência observada em 2000, quando o maior estoque de imigrantes é natural do estado de São Paulo (17,18\%).

Quanto aos destinos, os emigrantes cearenses permaneceram se dirigindo, preferencialmente, para a região Sudeste $(48,99 \%)$ e Nordeste $(21,38 \%)$, com menor intensidade para o Centro Oeste $(13,35 \%)$, Norte $(13,29 \%)$ e Sul $(2,99 \%)$. Por Unidade da 
Federação, São Paulo (32,68\%) continuou como a principal área de atração (desde 1980), seguido de longe pelo Rio de Janeiro (13,19\%), Pará (6,78\%) e o Distrito Federal (6,03\%).

Tabela 7 - Estoque de imigrantes, emigrantes e saldos migratórios interestaduais Estado do Ceará - 2010

\begin{tabular}{|c|c|c|c|c|c|}
\hline $\begin{array}{l}\text { Regiões e } \\
\text { Estados }\end{array}$ & $\begin{array}{c}\text { Imigrantes } \\
\text { (I) }\end{array}$ & $(\%)$ & Emigrantes (E) & $(\%)$ & $\begin{array}{c}\text { Saldos } \\
\text { (I-E) }\end{array}$ \\
\hline Rondônia & 2.379 & 0,62 & 22.835 & 1,53 & -20.457 \\
\hline Acre & 2.054 & 0,53 & 6.375 & 0,43 & -4.321 \\
\hline Amazonas & 7.073 & 1,84 & 30.366 & 2,04 & -23.293 \\
\hline Roraima & 727 & 0,19 & 12.803 & 0,86 & -12.076 \\
\hline Pará & 18.718 & 4,86 & 101.084 & 6,78 & -82.365 \\
\hline Amapá & 1.182 & 0,31 & 5.391 & 0,36 & -4.209 \\
\hline Tocantins & 962 & 0,25 & 19.386 & 1,30 & -18.423 \\
\hline NORTE & 33.096 & 8,59 & 198.241 & 13,29 & -165.145 \\
\hline Maranhão & 31.097 & 8,07 & 89.496 & 6,00 & -58.399 \\
\hline Piauí & 43.867 & 11,39 & 58.038 & 3,89 & -14.171 \\
\hline Rio Grande do Norte & 34.576 & 8,98 & 37.475 & 2,51 & -2.898 \\
\hline Paraíba & 38.683 & 10,04 & 22.798 & 1,53 & 15.885 \\
\hline Pernambuco & 48.327 & 12,55 & 54.802 & 3,67 & -6.475 \\
\hline Alagoas & 9.434 & 2,45 & 5.855 & 0,39 & 3.580 \\
\hline Sergipe & 1.591 & 0,41 & 3.481 & 0,23 & -1.890 \\
\hline Bahia & 15.801 & 4,10 & 47.047 & 3,15 & -31.247 \\
\hline NORDESTE & 223.376 & 58,00 & 318.991 & 21,38 & -95.615 \\
\hline Minas Gerais & 6.369 & 1,65 & 37.568 & 2,52 & -31.199 \\
\hline Espírito Santo & 1.009 & 0,26 & 8.971 & 0,60 & -7.963 \\
\hline Rio de Janeiro & 26.480 & 6,88 & 196.804 & 13,19 & -170.325 \\
\hline São Paulo & 66.137 & 17,17 & 487.620 & 32,68 & -421.483 \\
\hline SUDESTE & 99.993 & 25,96 & 730.963 & 48,99 & -630.970 \\
\hline Paraná & 4.917 & 1,28 & 25.675 & 1,72 & -20.757 \\
\hline Santa Catarina & 1.583 & 0,41 & 11.319 & 0,76 & -9.736 \\
\hline Rio Grande do Sul & 4.585 & 1,19 & 7.662 & 0,51 & -3.077 \\
\hline SUL & 11.085 & 2,88 & 44.656 & 2,99 & -33.570 \\
\hline Mato Grosso do Sul & 1.487 & 0,39 & 19.398 & 1,30 & -17.911 \\
\hline Mato Grosso & 1.374 & 0,36 & 20.692 & 1,39 & -19.318 \\
\hline Goiás & 4.398 & 1,14 & 69.124 & 4,63 & -64.726 \\
\hline Distrito Federal & 10.303 & 2,68 & 89.912 & 6,03 & -79.609 \\
\hline CENTRO-OESTE & 17.562 & 4,56 & 199.126 & 13,35 & -181.564 \\
\hline TOTAL CEARÁ & 385.112 & 100,00 & $\mathbf{1 . 4 9 1 . 9 7 6}$ & 100,00 & -1.106 .864 \\
\hline
\end{tabular}

Fonte: Elaboração própria a partir dos Microdados do Censo Demográfico 2010 (IBGE).

O que se percebe é que a despeito das políticas de desenvolvimento regionais adotadas desde o Império, passando pela criação da SUDENE, e as políticas de industrialização do Ceará, somente a partir da primeira década do século XXI, num quadro caracterizado pela ausência de uma política nacional de desenvolvimento e de crescimento econômico modesto, quando comparado às décadas de 1960 e 1970, a pobreza, a extrema pobreza e exclusão social foram minoradas (SCALON 2005; NERI 2007; QUADROS 2011). 
Gráfico 3 - Saldos migratórios interestaduais, segundo períodos censitários - Estado do Ceará - 1950-2010

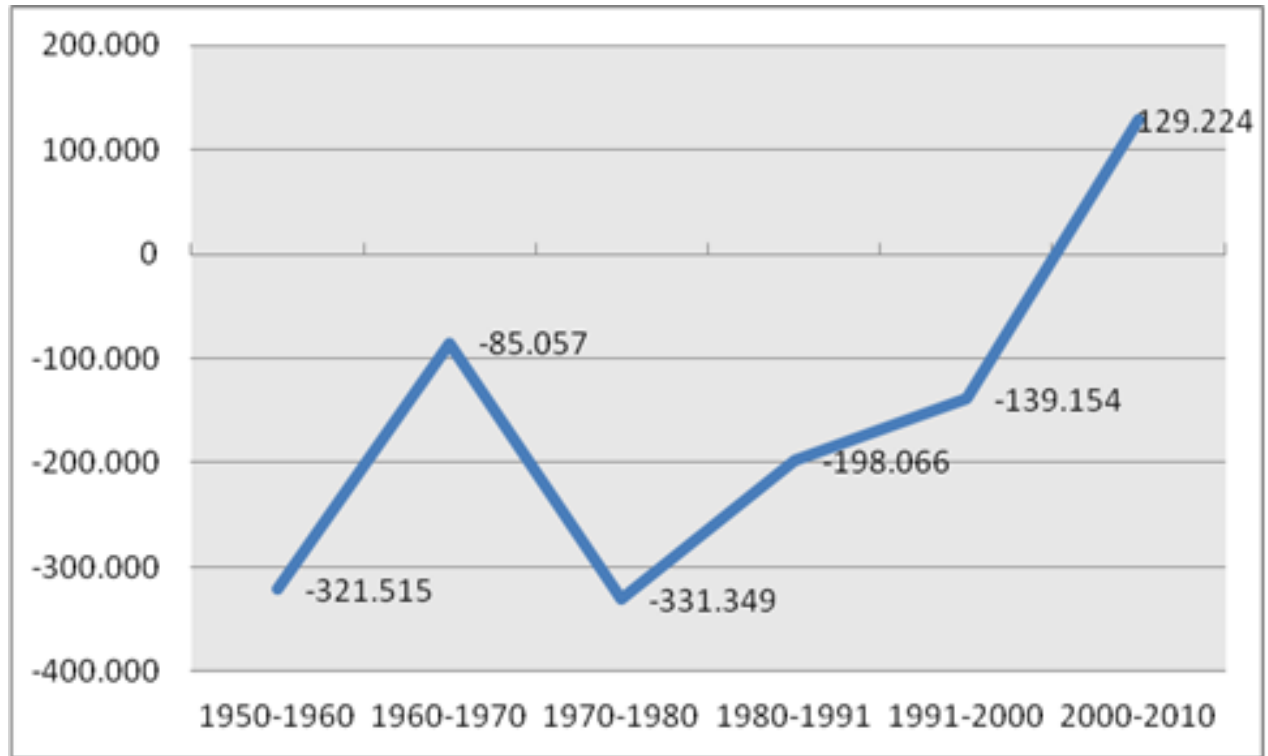

Fonte: Elaboração própria a partir do Anuário Estatístico do Brasil - 1950 e 1960; Microdados dos Censos Demográficos de 1970, 1980, 1991, 2000 e 2010 (IBGE).

A partir deste diagnóstico favorável a economia e a sociedade brasileira e cearense, do ponto de vista migratório, constatou-se importante inflexão nos movimentos migratórios do e para o Ceará. Durante os decênios em estudo, somente entre 2000/2010, atestou-se, ao mesmo tempo, diminuição nas saídas e aumento nas entradas resultando, pela primeira vez, em saldo migratório positivo de 129.224 mil pessoas, com o maior pico de perdas nos anos 1970 (331.349 migrantes) e, início da tendência à ruptura, a partir da década de 1980 (Gráfico 3).

\section{Conclusão}

O quadro evolutivo das migrações interestaduais cearenses revelou especificidades e alterações no volume e direção dos fluxos. Assim, o panorama descritivo e sistematizado apontou para a manutenção de algumas tendências e rupturas em outras.

No período de 1950 a 2010, o Ceará sempre apresentou saldo migratório acumulado negativo, mas desde os anos 1980 foi possível detectar duas tendências gerais: i) período 1950-1980 - perda expressiva de população; ii) 1980-2010 - arrefecimento nas perdas, destacando-se o período 2000/2010, com saldo migratório positivo.

Com isso, a análise no tempo e espaço mostrou que, em 1950, os maiores saldos negativos foram com a região Norte, mas em nível estadual foi para o estado vizinho do Piauí.

Ao longo dos anos 1950 as saídas se intensificaram e em 1960 os maiores saldos 
negativos efetuou-se com a região Nordeste. Por estado, o Ceará passou a perder mais população para o Maranhão.

Em 1970 observaram-se mudanças no destino migratório, com as maiores perdas, pela primeira vez, registradas com a região Sudeste. Em nível estadual, o estado de São Paulo ainda não figurava como principal polo de atração, permanecendo o Maranhão.

Nos anos 1970 - decênio de maior evasão - o fluxo migratório se dirigiu em massa para o Sudeste, especialmente para o estado de São Paulo que, desde 1980, contempla o maior número de naturais do Ceará residindo nesta Unidade da Federação.

A partir dos anos 1980, lentamente, constatou-se o declínio nas perdas populacionais. No caso do destino, não houve mudanças, com os maiores saldos negativos registrados com o Sudeste e o estado de São Paulo, em 1991.

Em 2000 as perdas se mantiveram, mas em ritmo menos intenso quando comparado ao período 1950-1980. Para a região Sudeste e o estado de São Paulo, o Ceará permaneceu perdendo mais população.

O ano de 2010 é revelador de surpresas e inflexões. Ao longo dos decênios em estudo, somente entre 2000/2010, constatou-se, ao mesmo tempo, declínio nas saídas e aumento nas entradas, resultando, pela primeira vez, em saldo migratório positivo. As maiores perdas continuaram para o Sudeste e o estado de São Paulo, mas quando comparado ao decênio anterior, estas apresentaram descenso.

Em síntese, durante as seis décadas em análise, constataram-se dois grandes eixos nas migrações interestaduais cearenses: i) um primeiro vetor, com raízes históricas, se dirigiu no sentido da região Norte (Pará e Amazonas) e Nordeste (Maranhão e Piauí), predominando até 1970; ii) um segundo vetor, num contexto contemporâneo - seguiu em direção ao Sudeste (São Paulo e Rio de Janeiro) e prevalece até os dias atuais. Ademais, em termos de volume, as principais tendências revelaram que, desde os anos 1980, paulatinamente, a cada Censo Demográfico, o Ceará diminui as suas perdas populacionais.

\section{Referências Bibliográficas}

ALENCAR, J. S; ALVES. M. O. O subespaço semi-árido no contexto de uma estratégia de desenvolvimento para o Nordeste. In: Cleide Bernal. (Org.). A economia do Nordeste na fase contemporânea. 1 ed. Fortaleza: Banco do Nordeste do Brasil/Edições UFC, 2006, v., p. 235259.

BAENINGER, R. Migrações internas no Brasil no século 21: entre o local e o global. In: XVIII Encontro Nacional de Estudos Populacionais, 2012, Águas de Lindóia - SP. Anais do XVIII Encontro Nacional de Estudos Populacionais - ABEP. 
BASSANEZI, M. S. C. B. Migrantes no Brasil da segunda metade do século XIX. In: Encontro Nacional da Associação Brasileira de Estudos Populacionais - ABEP, XII., 2000, Caxambu/MG. Anais... Belo Horizonte: ABEP, 2000.

BRITO, F. Minas e o Nordeste, perspectivas migratórias dos dois grandes reservatórios de força de trabalho. II Encontro Nacional de Migração, ABEP/GT de Migração, 1999.

CANO, W. Concentração e desconcentração industrial no Brasil: 1970/95. In: Revista econômica e sociedade. São Paulo, n.8, p. 101-141, jun.1997.

GUIMARÃES NETO, L. O Nordeste, o planejamento regional e as armadilhas da macroeconomia. In Revista Estudos e Pesquisas. N.67, p.109-151, Salvador: SEI, 2004.

MARTINE, G. A redistribuição espacial da população brasileira durante a década de 80 . Rio de Janeiro: IPEA/DIPES, texto para discussão n. 329, jan, 1994.

MASSEY, D. S. Social Structure, Household Strategies, and the Cumulative Causation of Migration. Population Index 56, 1, p. 3-26, 1990.

NEVES. F. C. Getúlio e a seca: políticas emergenciais na era Vargas. Revista Brasileira de História. São Paulo, v. 21, no 40, p. 107-131. 2001.

PATARRA, N. L. Movimentos Migratórios no Brasil: tempos e espaços. Textos para discussão Escola Nacional de Estatística Número 7. ENCE, Rio de Janeiro, 2003a.

PONTES, P. A.; CAMBOTA, J. N.; BIDERMAN, C.. Incentivos estaduais à indústria de transformação e a geração de emprego: um estudo de caso para o estado do Ceará. In: EnANPAD, 2011, Rio de Janeiro. Anais de EnANPAD 2011.

QUEIROZ, S. N. de.; BAENINGER, R. Tendências recentes das migrações cearenses: o caso da migração de retorno. In: Rosana Aparecida Baeninger. (Org.). População e Cidades: Subsídios para o Planejamento e para as Políticas Sociais. $1^{a}$ ed. Campinas-SP: Núcleo de Estudos de População-NEPO, 2010, v. 1, p. 253-275.

ROSADO V (org.). Memorial da seca. Diversos autores. Mossoró, RN, Fundação Guimarães Duque, Coleção Mossoroense, V. CLXIII, 1981.

SINGER. P. Migrações internas: considerações teóricas sobre o seu estudo. In: MOURA, Hélio A. de (Org.). Migrações internas: textos selecionados. Fortaleza: BNB, 1980, Tomo 1, p. 211-244.

TROVÃO, J. R. O processo de ocupação do território maranhense. São Luís: Cadernos IMESC 5 (INSTITUTO MARANHENSE DE ESTUDOS SOCIOECONÔMICOS E CARTOGRÁFICOS), 2008. 